\title{
Study of HOTAIR LncRNA in AML patients in context to FLT3-ITD and NPM1 mutations status
}

\author{
Mona Salah', Hamdy Zawam², Neven Bahaa Fouad', Nohair Soliman¹ and \\ Fatma Abdel Wahab Abdel Maksoud ${ }^{1 *}$ (D)
}

\begin{abstract}
Background: Long non-coding RNAs (LnCRNAs) have recently been considered promising biomarkers for oncogenesis due to their epigenetic regulatory effects. HOTAIR is one of the oncogenic LncRNAs that was previously studied in different non-hematological malignancies. The current study set out to detect the expression level of HOTAIR LnCRNA in AML patients concerning their clinical characteristics, laboratory data, FLT3-ITD, and NPM1 mutations, as well as treatment outcome. This study included quantitative detection of HOTAIR gene expression in 47 cases of AML using quantitative reverse transcription polymerase chain reaction, as well as NPM1 and FLT3-ITD genotyping.
\end{abstract}

Results: The HOTAIR expression was significantly higher in AML patients 6.87 (0.001) than in normal controls 1.66 (0.004-6.82) ( $p$ 0.007). The HOTAIR expression level was affected by chemotherapy, and it was correlated to hemoglobin level ( $p$ 0.001), age, total leukocytic count ( $p$ 0.022), and NPM1 mutation ( $p$ 0.017). HOTAIR gene expression level showed a correlation to relapse-free survival in the study group ( $p$ 0.04).

Conclusion: HOTAIR is overexpressed in patients with acute myeloid leukemia (AML). HOTAIR pre-treatment and post-chemotherapy gene expression levels can predict chemosensitivity and relapse.

Keywords: HOTAIR, LnCRNA, AML, NPM1, FLT3-ITD

\section{Background}

The availability of whole-genome sequencing enabled discovering the genomic landscape and the non-coding genes, representing 98\% of the human genome $[1,2]$. Long non-coding RNAs (LncRNAs) are non-coding RNA transcripts that exceed 200 base pairs (bp) in length. LncRNAs are located and transcribed from different genomic loci and are designated as intergenic and intronic LncRNAs from intergenic regions and introns, respectively [3].

HOX transcript antisense intergenic RNA (HOTAIR) is a 2158-bp LncRNA transcribed from the antisense

\footnotetext{
* Correspondence: fatma.abdelwahab@cu.edu.eg

${ }^{1}$ Clinical and Chemical Pathology Department, Kasr Al-Ainy School of

Medicine, Cairo University, Kasr Al-Ainy St., 11562 Giza, Egypt

Full list of author information is available at the end of the article
}

strand of the homeobox $\mathrm{C}$ gene on chromosome 12 [4]. HOTAIR acts in trans on the HOX D locus of chromosome 2 through chromatin-remodeling enzymes [5]. It is a novel prognostic biomarker, especially for the potential metastatic prediction [6]. The HOTAIR overexpression has been shown in patients with colorectal cancer and hepatocellular carcinoma [7]. It has been reported that the degree of HOTAIR expression has an impact on the survival rate of breast cancer patients [8]. It has been demonstrated that inhibiting HOTAIR promotes cancer cell apoptosis [9].

The Fms-like tyrosine kinase three-gene (FLT3) encodes a tyrosine kinase expressed on hematopoietic progenitor cells. FLT3 is the most common mutated gene in AML [10]. The most common FLT3 mutation in AML is an internal tandem duplication (FLT3-ITD) in 
the juxtamembrane domain of the FLT3 gene, resulting in uncontrolled hematopoietic cell proliferation mediated by FLT3/STAT5 [11].

The Nucleophosmin 1 gene (NPM1) mutations have been described as one of the most frequent genetic lesions in AML, occurring in about $40 \%$ of normal karyotype AML [12]. The NPM1 gene encodes a nucleocytoplasmic shuttling protein that regulates the ARF-p53 tumor-suppressor pathway [13]. NPM1 mutations result in an abnormal cytoplasmic accumulation of the NPM1 protein [14]. NPM1 mutations have been associated with distinct LncRNA signatures in AML [15].

The present study aims to determine the HOTAIR expression level in AML patients using quantitative realtime reverse transcription PCR and correlate the expression level with NPM1 and FLT-ITD mutations, as well as laboratory data and treatment outcome.

\section{Methods}

This research aims to examine the HOTAIR gene expression in AML and the association between HOTAIR expression and clinicopathological data from patients, including the commonly tested mutations in our lab (e.g., NPM1 and FLT3-ITD).

The study included 47 patients with AML from Medical Oncology Department. The post-chemotherapy level of HOTAIR gene expression was compared to pretreatment levels and treatment outcome.

The controls were age- and sex-matched volunteers referred to the Clinical Pathology Department for bone marrow analysis before splenectomy for hypersplenism. Informed consent was obtained from all subjects for being included in the study.

The following are the inclusion criteria:

- All cases of AML above 18 years old (adults)

- AML with recurrent cytogenetic abnormalities

- AML NOS

- Both males and females

The following are the exclusion criteria:

- Pediatric age group

- Therapy-related AML

- AML with myelodysplasia-related changes

- History of myeloproliferative neoplasms (e.g., chronic myeloid leukemia or primary myelofibrosis)

The study included the following:

- Detection of NPM1 and FLT3-ITD mutations by high-resolution melting (HRM) analysis

- Quantitative detection of HOTAIR gene expression
- Follow-up of cases after treatment (standard AML chemotherapy $7+3$ protocol)

- HOTAIR gene expression level detection in cases with adequate post-chemotherapy bone marrow samples (adequate RNA extract)

\section{NPM1 and FLT3-ITD mutation screening by high- resolution melting analysis}

Genomic DNA was extracted from bone marrow samples using the QIAamp ${ }^{\circ}$ DNA Blood Mini Kit (Cat No:51104). Twenty-five nanogram of the DNA was used in the PCR reaction, which was performed using MeltDoctor $^{\mathrm{rm}}$ HRM Master Mix (ABI Product Number/ 4415440). The primers that had been used in the genotyping of NPM1 and FLT3-ITD were as follows: NPM1 forward 5' -TGGTTCCTTAACCACATTTCTTT-3' and reverse 5'-GGACAACACATTCTTGGC-3' [16], while for FLT3-ITD: forward 5'-TGCAGAACTG CCTATT CCTAACTGA-3' and reverse 5' -TTCCATAAGCTGTT GCGTTCATCA-3' [17]. The reaction plate was run using the Applied Biosystems 7500 Fast Real-Time PCR under the following conditions: holding $95^{\circ} \mathrm{C}$ for 10 min, 50 cycles of denaturation at $9560^{\circ} \mathrm{C}$ for $15 \mathrm{~s}$, and annealing/extension at $60^{\circ} \mathrm{C}$ for $1 \mathrm{~min}$. The melting curve conditions were as follows: (i) denaturation at $95^{\circ} \mathrm{C}$ for $30 \mathrm{~s}$, (ii) annealing at $60^{\circ} \mathrm{C}$ for $1 \mathrm{~min}$, (iii) denaturation at $95^{\circ} \mathrm{C}$ for $30 \mathrm{~s}$, and (iv) annealing at $60^{\circ} \mathrm{C}$ for $15 \mathrm{~s}[16,17]$.

\section{HOTAIR gene expression}

Total RNA was extracted from bone marrow mononuclear cells using the QlAamp RNA Blood Mini Kit (Cat No. 52304), followed by cDNA synthesis using the RevertAid First Strand cDNA Synthesis Kit (Cat No: K1622). HOTAIR gene expression was performed using the RT qPCR technique, with b-actin serving as a housekeeping gene. SYBR Green qPCR Master Mix (Cat No: K0221) was used. The primers that had been used in the gene expression experiment were as follows: HOTAIR, forward 5' ${ }^{\prime}$-CAGTGGGGAACTCTGACTCG-3' and reverse $5^{\prime}$-GTGCCTGGTGCTCTCTTACC-3'; $\beta$-actin, forward 5'-CACCATTGGCAATGAGCGGTTCC-3' and reverse 5'-GTAGTTTCGTGG ATGCCACAGG-3' [18]. The reaction conditions were as follows: (i) holding at $95^{\circ} \mathrm{C}$ for $10 \mathrm{~min}$, (ii) 10 cycles of denaturation at $95^{\circ} \mathrm{C}$ for $15 \mathrm{~s}$, (iii) annealing/extension at $95-60^{\circ} \mathrm{C}$ (touch-down) for $1 \mathrm{~min}$, (iv) another 40 cycles of denaturation at $95^{\circ} \mathrm{C}$ for $30 \mathrm{~s}$, (v) annealing at $56{ }^{\circ} \mathrm{C}$ for $1 \mathrm{~min}$, and (vi) extension at $72^{\circ} \mathrm{C}$ for $30 \mathrm{~s}$. The expression was calculated using the $2^{-\Delta \Delta C T}$ formula, where $\Delta \mathrm{CT}=\mathrm{Ct}$ HOTAIR $-\mathrm{Ct} \beta$ actin and $\Delta \Delta \mathrm{CT}=\Delta \mathrm{CT}$ sample $-\Delta \mathrm{CT}$ control (reference sample) [19]. 


\section{Statistical analysis}

Statistical analysis was carried out using SPSS v25. The Kruskal-Wallis test was used to compare cases and controls, and Pearson correlation was used to associate the clinicopathological features with HOTAIR gene expression. P values $<0.05$ are considered significant. Survival rates (overall survival and disease-free survival) were calculated by Kaplan Mayer (log-rank) analysis.

\section{Results}

The study involved 47 participants, 26 males and 21 females. Their age ranged from 18 to 83 years, with a median of 36 years. According to the FAB classification, 29 cases were M2 and M4. The summary of hematological data is shown in Table 1.

Results of NPM1 and FLT3-ITD mutation screening by HRM HRM analysis was done using the ABI7500 fast HRM software version 2.02. Previous studies validated the technique of HRM for detecting NPM1 and FLT3ITD $[16,17]$.

Figures 1 and 2 illustrate the melting curves and difference plots between controls, wild genotype, and mutant genotypes. Wild genotype in both genes was found in 22 cases. In 5 cases, mutations in both genes were found. Five cases had NPM1 mutant and FLT3-ITD wild genotypes, 14 cases had NPM1 wild and FLT3-ITD mutant genotypes, and 1 case was not examined for NPM1 or FLT3-ITD mutations (failed DNA extraction).

\section{HOTAIR detection of gene expression in AML cases and controls}

There was a substantial difference in the median HOTAIR gene expression levels between cases and controls (Kruskal-Wallis, p 0.007). HOTAIR expression in cases varied from 0.001 to 2702 with a median expression of 6.87 , while it ranged from 0.004 to 6.82 with a median expression of 1.66 in controls, as illustrated in Table 2.

The correlation of HOTAIR expression level to age, gender, and different hematological data was illustrated in Table 3. High HOTAIR levels were associated with

Table 1 Age and laboratory results of AML cases

\begin{tabular}{ll}
\hline Laboratory data & Median/range \\
\hline $\mathrm{TLC}\left(\times 10^{3} / \mu \mathrm{L}\right)$ & $26.9(0.6-465)$ \\
$\mathrm{Hb}(\mathrm{g} / \mathrm{dL})$ & $8.45(4.2-16.6)$ \\
$\mathrm{Plt}\left(\times 10^{3} / \mu \mathrm{L}\right)$ & $44(6-334)$ \\
Blast\% & $70(20-100)$ \\
Cytogenetic results by FISH & \\
$\mathrm{t}(8 ; 21)$ & Positive $2 / 47$ cases \\
$\mathrm{t}(15 ; 17)$ & Positive $2 / 47$ cases \\
\hline
\end{tabular}

higher hemoglobin $(\mathrm{Hb})$ levels, lower total leucocytic count (TLC), and lower age groups. Other clinicopathological factors, including age, gender, platelet count (PLT), and complete remission (CR), were not significantly correlated. Regarding NPM1 and FLT3 mutation status, all the NPM1 mutant/FLT3-ITD wild cases expressed low levels of HOTAIR $(\mathrm{p}=0.017)$. Thirty-seven cases started to receive standard induction therapy; 18/37 cases achieved CR, while the remaining cases were deemed unfit to start induction.

HOTAIR expression in AML patients prior and postchemotherapy (16/37) (see Table 4)

Cases with a high expression demonstrated a substantial reduction after $C R(p=0.028)$. However, cases with a low HOTAIR expression group showed a non-significant increase in HOTAIR expression following CR. Patients who failed to achieve CR, whether they had low or high HOTAIR expression, exhibited a non-significant decrease in HOTAIR gene expression after induction.

\section{Combined effect of HOTAIR expression and NPM1/FLT3- ITD mutation analysis on CR achievement and poor outcome (see Table 5)}

The NPM1 mutant/FLT3-ITD mutant group (100\%) achieved the highest $\mathrm{CR}$ rate among the low expression group, while the lowest rate was found in the NPM1wild/FLT3-ITD mutant group (16\%). Among the high expression group, CR was maximally achieved in the NPM1-wild/FLT3-ITD mutant (63\%). Poor outcome was defined in the study by death, relapse, and failed induction. The level of HOTAIR expression did not affect the poor outcome percentages except in the NPM1-wild/FLT3-ITD mutant genotype, where the high expression was associated with diminished poor outcome percentages.

\section{Overall survival}

According to Table 6, Kaplan-Meier survival analysis revealed that patients in the lower TLC group and those who achieved CR had a better overall survival (OS) ( $p=0.05, p=0.004$, respectively).

\section{Relapse-free survival}

The 18 patients who achieved CR after induction therapy were monitored for 12 months to assess relapse-free survival (RFS). RFS factors such as age, gender, Hb, PLT, blasts percent, HOTAIR expression, and NPM1/FLT3 gene mutation status and data are summarized in Table 7. Seven patients relapsed during the follow-up period, with a median RFS of 9 months.

HOTAIR expression levels had a significant outcome on RFS; patients with a high HOTAIR expression showed a higher RFS rate than those with low HOTAIR 

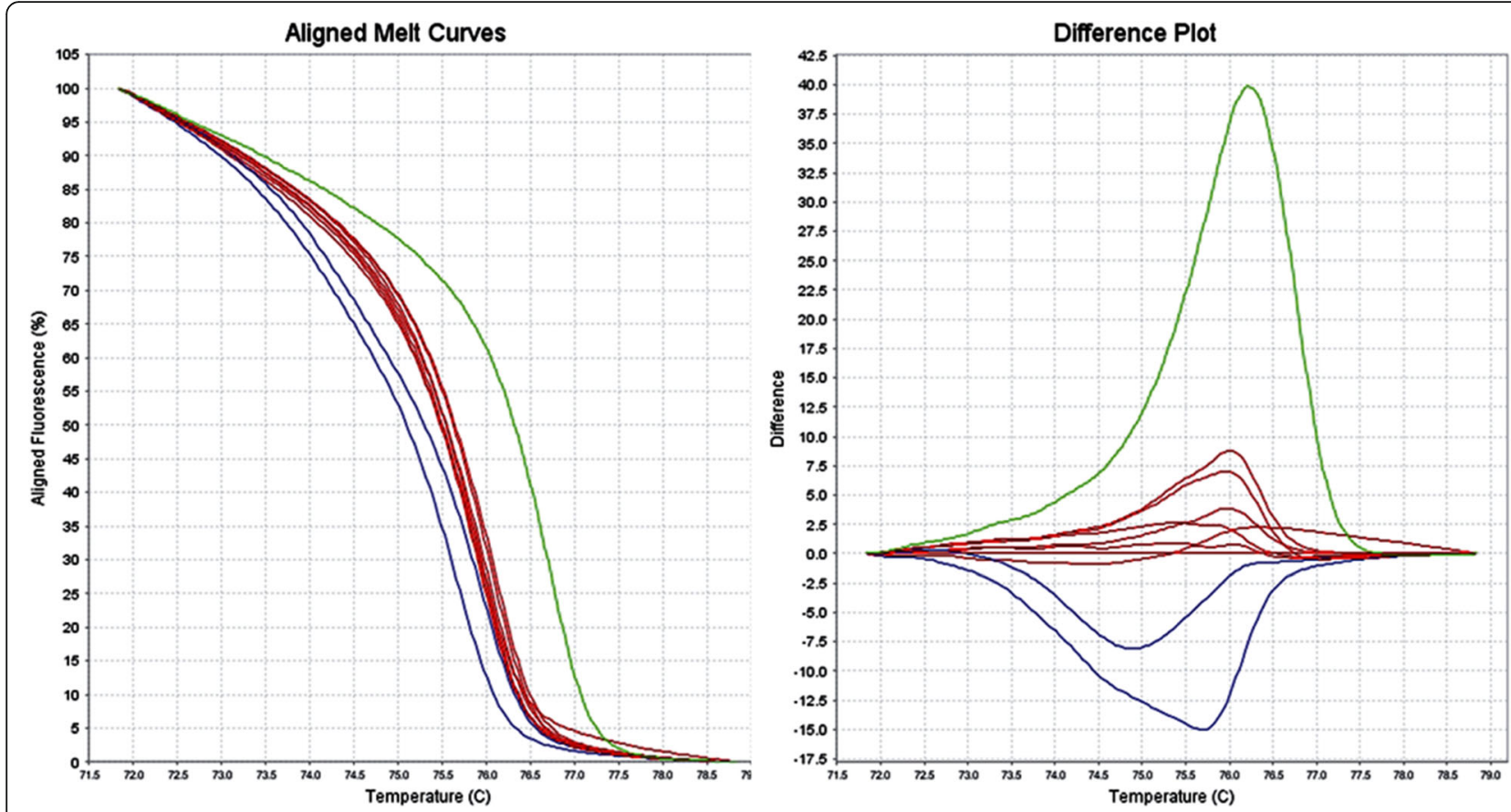

Fig. 1 HRM difference plot curve and aligned melting curve of NPM1. The wild genotype cases (red) and there are two mutant cases (blue and green)
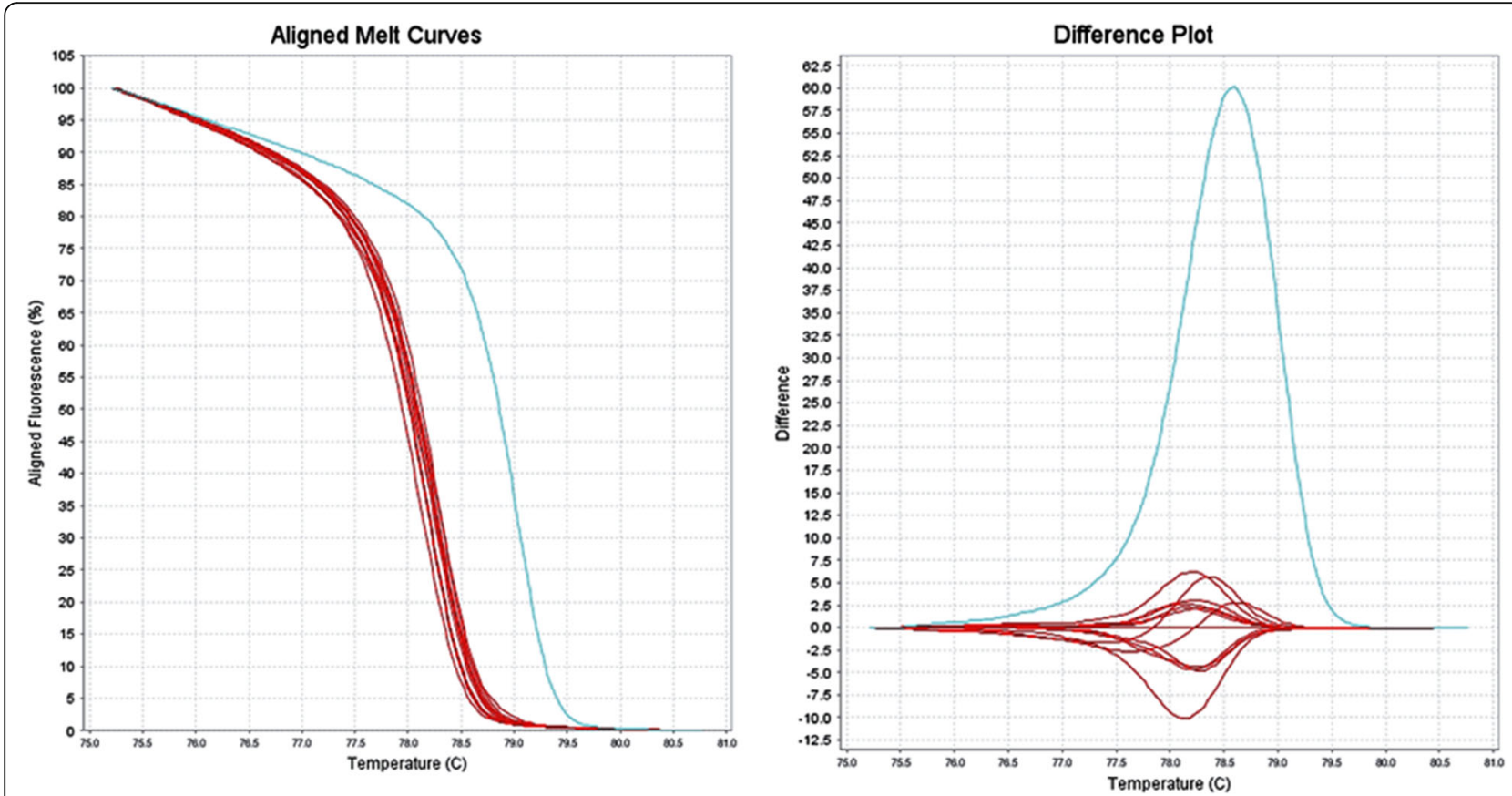

Fig. 2 HRM difference plot curve and aligned melting curve of FLT3-ITD. The wild genotype (red) and there is one mutant case (blue) 
Table 2 HOTAIR gene expression in cases and controls

\begin{tabular}{llll}
\hline & Median & Range & $\boldsymbol{p}$ value \\
\hline Cases & 6.87 & $0.001-2702$ & 0.007 \\
Controls & 1.66 & $0.004-6.82$ & \\
\hline
\end{tabular}

expression levels (p 0.04). The median RFS was 11 months in the high HOTAIR expression group, compared to 7 months in the low expression group. Regarding the NPM1 and FLT3-ITD mutation screening results, the low HOTAIR expression group in NPM1WT/FLT3-WT cases $(n=4)$ had a higher RFS than the

Table 3 Correlation of HOTAIR gene expression to AML patient's clinicopathological parameters

\begin{tabular}{|c|c|c|c|}
\hline & \multicolumn{2}{|c|}{ Expression } & \multirow[t]{2}{*}{ Sig. } \\
\hline & Low & High & \\
\hline \multicolumn{4}{|l|}{ Gender } \\
\hline Male & 12 & 14 & 0.671 \\
\hline Female & 11 & 10 & \\
\hline \multicolumn{4}{|l|}{ Age } \\
\hline$<50$ & 13 & 20 & 0.046 \\
\hline$\geq 50$ & 10 & 4 & \\
\hline \multicolumn{4}{|l|}{ TLC } \\
\hline$<50$ & 12 & 20 & 0.022 \\
\hline$\geq 50$ & 11 & 4 & \\
\hline \multicolumn{4}{|l|}{$\mathrm{HB}$} \\
\hline$<8$ & 13 & 3 & 0.001 \\
\hline$\geq 8$ & 10 & 21 & \\
\hline \multicolumn{4}{|l|}{ PLT } \\
\hline$<50$ & 12 & 14 & 0.34 \\
\hline$\geq 50$ & 11 & 10 & \\
\hline \multicolumn{4}{|l|}{ Wild-FLT3 } \\
\hline Wild NPM1 & 9 & 13 & 0.017 \\
\hline Mutant NPM1 & 5 & 0 & \\
\hline \multicolumn{4}{|l|}{ FLT3-ITD } \\
\hline Wild NPM1 & 6 & 8 & 0.9 \\
\hline Mutant NPM1 & 2 & 3 & \\
\hline \multicolumn{4}{|l|}{$C R$} \\
\hline Achieved & 8 & 10 & 0.318 \\
\hline Failed & 15 & 14 & \\
\hline \multicolumn{4}{|l|}{ Blasts } \\
\hline$<50$ & 11 & 6 & 0.104 \\
\hline$\geq 50$ & 12 & 18 & \\
\hline \multicolumn{4}{|l|}{$F A B$} \\
\hline M2-M4 & 8 & 10 & 0.627 \\
\hline Others & 11 & 12 & \\
\hline
\end{tabular}

Table 4 Combined effect of HOTAIR and mutation analysis on CR and poor outcome

\begin{tabular}{llllll}
\hline & \multicolumn{2}{c}{$\mathbf{C R}$} & & & \multicolumn{2}{c}{ Outcome } \\
& $\mathbf{C R}$ & $\%$ & & Poor & $\%$ \\
\hline Low expression & & & & \\
NPM1-WT/FLT3WT & $4 / 9$ & $44 \%$ & & $7 / 9$ & $89 \%$ \\
NPM1-mut/FLT3-mut & $2 / 2$ & $100 \%$ & $2 / 2$ & 100 \\
NPM1-mut/FLT3-WT & $1 / 5$ & $20 \%$ & $5 / 5$ & $100 \%$ \\
NPM1-WT/FLT3-mut & $1 / 6$ & $16 \%$ & $5 / 6$ & $84 \%$ \\
High expression & & & & \\
NPM1-WT/FLT3-WT & $4 / 13$ & $38 \%$ & $10 / 13$ & $62 \%$ \\
NPM1-mut/FLT3-mut & $1 / 3$ & $33 \%$ & $3 / 3$ & $100 \%$ \\
NPM1-WT/FLT-mut & $5 / 8$ & $63 \%$ & $3 / 8$ & 37.5 \\
\hline
\end{tabular}

high expression group $(n=2)$. In all cases with FLT3ITD, the high HOTAIR expression group had a higher RFS than the low expression group.

\section{Discussion}

Mutations and misregulation of long non-coding RNAs have been shown to play pivotal roles in oncogenesis. Alterations in LncRNA expression or mutations promote tumorigenesis and metastasis. LncRNAs carry considerable promise as cancer novel biomarkers and therapeutic targets [20].

Histones epigenetic modifications, such as acetylation and methylation, have been proved to be frequently deregulated in AML [21].

The effect of methylation is site-specific, for example, histone 3 lysine 4 (H3K4), activates gene expression. On the contrary, methylation of histone 3 lysine 9 (H3K9) or lysine 27 (H3K27) suppresses the transcription [22].

The PRC2 complex contains the three core protein subunits: enhancer of zeste homolog 2 (EZH2), embryonic ectoderm development, and SUZ12. EZH2 contains a SET domain that catalyzes trimethylation of histone $\mathrm{H} 3$ at lysine 27. HOTAIR binding to PRC2 is required for H3K27 trimethylation [23].

Through whole-genome sequencing, NPM1 mutations and FLT3-ITD were found to be associated with distinct LncRNA signatures [24].

HOTAIR was reported to act as a bridge between protein complexes, supporting chromatin silencing, including the PRC2 [5].

HOTAIR binds to and sequesters miR-193a competitively, modulates the expression of c-KIT in AML cells, promotes cell growth, and inhibits apoptosis [25].

Patients with NPM1 mutations proved to have a better outcome with increased complete remission and improved overall survival [26]. However, AML with FLT3 ITD carries a poor prognosis owing to its higher risk of relapse [27]. 
Table 5 HOTAIR expression basal level and after induction chemotherapy

\begin{tabular}{|c|c|c|c|c|c|}
\hline & \multicolumn{2}{|l|}{ Baseline } & \multicolumn{2}{|c|}{ After treatment } & \multirow[t]{2}{*}{$P$ value } \\
\hline & Median & Range & Median & Range & \\
\hline \multicolumn{6}{|l|}{$\begin{array}{l}\text { Patients who } \\
\text { achieved CR }\end{array}$} \\
\hline $\begin{array}{l}\text { High expression } \\
\text { group }(n=6)\end{array}$ & 29.84 & $10.91-255.82$ & 5.53 & $1.21-14.22$ & 0.024 \\
\hline $\begin{array}{l}\text { Low expression } \\
\text { group }(n=4)\end{array}$ & 1.04 & $0.46-6.71$ & 12.8 & $0.05-38.32$ & 0.144 \\
\hline Failed CR $(n=6)$ & 6.55 & $0.57-40.22$ & 1.01 & $0.92-30.57$ & 0.249 \\
\hline
\end{tabular}

Table 6 Overall survival

\begin{tabular}{|c|c|c|c|}
\hline & & Number (47) & Significance \\
\hline \multicolumn{4}{|l|}{ Gender } \\
\hline \multicolumn{2}{|l|}{ Male } & 26 & 0.888 \\
\hline \multicolumn{2}{|l|}{ Female } & 21 & \\
\hline \multicolumn{4}{|l|}{ Age } \\
\hline \multicolumn{2}{|l|}{$<50$} & 33 & 0.79 \\
\hline \multicolumn{2}{|l|}{$\geq 50$} & 14 & \\
\hline \multicolumn{4}{|l|}{ TLC } \\
\hline \multicolumn{2}{|l|}{$<50$} & 32 & 0.05 \\
\hline \multicolumn{2}{|l|}{$\geq 50$} & 15 & \\
\hline \multicolumn{4}{|l|}{$\mathrm{HB}$} \\
\hline \multicolumn{2}{|l|}{$<8$} & 16 & 0.67 \\
\hline \multicolumn{2}{|l|}{$\geq 8$} & 31 & \\
\hline \multicolumn{4}{|l|}{ PLT } \\
\hline \multicolumn{2}{|l|}{$<50$} & 26 & 0.7 \\
\hline \multicolumn{2}{|l|}{$\geq 50$} & $21^{\prime}$ & \\
\hline \multicolumn{4}{|l|}{ Expression } \\
\hline \multicolumn{2}{|l|}{ Low } & 23 & 0.628 \\
\hline \multicolumn{2}{|l|}{ High } & 24 & \\
\hline \multicolumn{4}{|l|}{ Blast } \\
\hline \multicolumn{2}{|l|}{$<50$} & 18 & 0.86 \\
\hline \multicolumn{2}{|l|}{$\geq 50$} & 29 & \\
\hline \multicolumn{4}{|c|}{ CR achievement } \\
\hline \multicolumn{2}{|l|}{ Yes } & 18 & 0.004 \\
\hline \multicolumn{2}{|l|}{ No } & 29 & \\
\hline \multicolumn{4}{|c|}{ Molecular results } \\
\hline \multirow[t]{2}{*}{ Wild-FLT3 } & Wild-NPM1 & 22 & 0.297 \\
\hline & Mutant-NPM1 & 5 & \\
\hline \multirow[t]{2}{*}{ FLT3-ITD } & Wild-NPM1 & 13 & \\
\hline & Mutant NPM1 & 6 & \\
\hline
\end{tabular}

Table 7 Relapse-free survival

\begin{tabular}{|c|c|c|c|c|}
\hline & & Number & Months & Significance \\
\hline All & & 18 & & \\
\hline \multicolumn{5}{|l|}{ Gender } \\
\hline Male & & 8 & 7 (4.9-9) & 0.912 \\
\hline Female & & 10 & $9(2.5-15)$ & \\
\hline \multicolumn{5}{|l|}{ Age } \\
\hline$<50$ & & 16 & $9(6.5-11.5)$ & 0.064 \\
\hline$\geq 50$ & & 2 & $5(6.4-11.4)$ & \\
\hline \multicolumn{5}{|l|}{ TLC } \\
\hline$<50$ & & 15 & $11(6.7-15.3)$ & 0.423 \\
\hline$\geq 50$ & & 3 & $9(6.4-11.5)$ & \\
\hline \multicolumn{5}{|l|}{ HB } \\
\hline$<8$ & & 3 & 9 & 0.875 \\
\hline$\geq 8$ & & 15 & $9(4.3-13.6)$ & \\
\hline \multicolumn{5}{|l|}{ PLT } \\
\hline$<50$ & & 11 & $9(7.3-10.7)$ & 0.552 \\
\hline$\geq 50$ & & 7 & $11(1.8-20)$ & \\
\hline \multicolumn{5}{|c|}{ Expression } \\
\hline Low & & 8 & 7 (4.5-9.5) & 0.04 \\
\hline High & & 19 & 11 & \\
\hline \multicolumn{5}{|l|}{ Blast } \\
\hline$<50$ & & 5 & $9(5.7-12.2)$ & 0.421 \\
\hline$\geq 50$ & & 13 & $9(6.4-11.5)$ & \\
\hline \multirow[t]{2}{*}{ Wild-FLT3 } & Wild-NPM1 & 8 & 9 & 0.194 \\
\hline & Mutant-NPM1 & 1 & 9 & \\
\hline \multirow[t]{2}{*}{ FLT3-ITD } & Wild-NPM1 & 6 & 12 & \\
\hline & Mutant NPM1 & 3 & 7 & \\
\hline
\end{tabular}

In this study, the expression of LncRNA and HOTAIR genes in 47 AML cases was estimated using the RT qPCR technique compared to controls. HOTAIR gene expression was higher in AML cases than in controls. These findings match those of a previous study, reporting that HOTAIR was overexpressed in AML patients [28].

According to HOTAIR median expression, the patients were classified into high and low expression groups. The high expression group showed a significant decrease after CR achievement $(p=0.024)$. These results mirror those of previous studies, which found that the HOTAIR expression was reduced after the achievement of CR [18]. However, a non-significant increase in the HOTAIR expression levels was noticed in the low expression group after CR achievement.

HOTAIR expression was affected by NPM1 and FLT3 mutations. All NPM1 mutant/FLT3-ITD wild cases were from the low HOTAIR expression group $(p=0.017)$, 
and $40 \%$ of the double NPM1/FLT3-ITD mutant cases were from the low expression group.

Since all NPM1 mutations increased cytoplasmic concentrations of NPM1 protein, NPM1 modulates stress response and growth suppression by binding to and stabilizing p53 and inhibiting MDM2 [29].

Zhai et al. had demonstrated that the p53 level was negatively correlated with HOTAIR in non-small cell lung carcinoma, suggesting a regulatory role for p53 in HOTAIR transcription. They discovered two p53 binding sites in the HOTAIR promoter region [30]. Similarly, the strong negative correlation between HOTAIR expression level and NPM1 mutation can be explained.

The HOTAIR expression was found to be positively correlated with hemoglobin level, which contradicts a previous study [18].

However, Shih and Kung explained that HOTAIR expression was upregulated by hypoxia, which is a common feature of all malignancies, including AML. This upregulation occurs through the hypoxia-responsive element in the HOTAIR promoter region, which is activated directly by hypoxia-induced factor-1 $\alpha$ (HIF $1 \alpha)$ [31]. HIF was found to upregulate $\delta$-aminolevulinate synthase, which catalyzes the first and rate-limiting reaction in the heme biosynthesis [32]. TLC was found to be inversely associated with HOTAIR expression $(p=$ 0.022). Previous studies on TLC and HOTAIR expression levels were controversial. Some researchers rated the TLC as high and low according to the highest normal count $\left(10 \times 10^{9} / \mathrm{L}\right)$ and found a positive correlation between HOTAIR expression and TLC [18].

However, Zhang et al. concluded that there is no correlation between the HOTAIR expression and TLC of AML patients. They classified the cases into high and low TLC groups by the count $100 \times 10^{9} / \mathrm{L}$ [33].

In this study, no significant correlation was found between patients' age, gender, platelet count, CR achievement, and HOTAIR expression.

CR achievement correlation with combined HOTAIR expression and mutation status revealed that among the low expression group, CR was maximally achieved in the NPM1 mutant/FLT3-ITD mutant genotype (100\%) and minimally in the NPM1 wild/FLT3-ITD mutant group. In contrast, among the high expression group, CR was maximally achieved in the NPM1-wild /FLT3-ITD mutant.

Just $20 \%$ of the NPM1-mutant/FLT-wild party achieved $\mathrm{CR}$, which is probably explained by other risk factors. Two patients had died before ending their induction, one patient was not fit to start therapy, and one patient missed his follow-up.

Patients in the NPM1 wild/FLT3-ITD mutant group experienced an unexplained rise in $\mathrm{CR}$ rates, despite having two weak prognostic factors: the FLT3-ITD mutation and elevated levels of HOTAIR oncogenic LncRNA expression.

Göllner et al. found that when FLT3-ITD mutationpositive leukemic cell lines after they have been cultured in media containing the kinase inhibitor for an extended time, they developed resistance to the kinase inhibitor and standard chemotherapeutics. Western blot identified complete loss of H3K27me3 in resistant cells. They also established that the mechanism of action is not restricted to the FLT3-ITD mutation [34].

The increased CR achievement rates with high HOTAIR expression in the FLT3-ITD-Mutant group were due to the interaction between HOTAIR LncRNA and its PRC2 binding function, which allows trimethylation of $\mathrm{H} 3 \mathrm{~K} 27$ and thus promotes chemo-sensitivity even in the presence of FLT3 ITD.

In this study, the OS of patients showed a high positive association with $C R$ achievement $(p=0.004)$ and a low TLC $(p=0.05)$. These findings corroborate a previous study [18].

The HOTAIR high expression group had a greater RFS $(p=0.024)$, surprisingly against previous literature [2]. This finding was corroborated with the postchemotherapy HOTAIR expression analysis, in which we found that the low expression group after achieving CR had higher HOTAIR levels than at diagnosis, and 3/ 4 of patients relapsed during follow-up, implying that post-treatment HOTAIR expression levels may serve as an early predictor of the relapse susceptibility.

Poor outcome was found in all combinations of NPM1and FLT3-ITD results regardless of the HOTAIR expression level except patients with FLT3-ITD mutant/ NPM1-wild populations, where the poor outcome ameliorated from $84 \%$ in patients with low HOTAIR expression levels to $62 \%$ in patients with high HOTAIR expression levels. However, this improvement was not statistically important. It can be attributed to our finding of increased chemo-sensitivity in the group with high HOTAIR expression in the presence of FLT3-ITD mutation.

\section{Conclusion}

In conclusion, HOTAIR expression levels were significantly higher in AML patients than in normal controls. According to the median of HOTAIR expression, patients were divided into high and low groups. Expression in the high group was markedly reduced after induction therapy and CR achievement. HOTAIR expression level correlated strongly with the $\mathrm{Hb}$ level at diagnosis, but not with the presence of the favorable mutation group (NPM1 mutation-FLT3 IDT wild-type), age, and TLC. Follow-up of patients revealed that our patients' overall survival was affected by TLC and CR achievement. A higher relapse rate was found in the low HOTAIR expression group. 


\section{Abbreviations}

AML: Acute myeloid leukemia; ARF: ADP-ribosylation factor; CR: Complete remission; CT: Threshold cycle; EED: Embryonic ectoderm development; EZH2: Enhancer of zeste homolog 2; FAB: French-American-British; FLT3ITD: Fms-like tyrosine kinase 3 gene internal tandem duplication; H3K4: Histone 3 lysine 4; H3K9: Histone 3 lysine 9; H3K27: Histone 3 lysine 9; Hb: Hemoglobin; HIF1a: Hypoxia-induced factor-1 a; HOTAIR: HOX transcript antisense intergenic RNA; HRM: High-resolution melting analysis;

LncRNAs: Long non-coding RNAs; MDM2: Mouse double minute 2 homolog; OS: Overall survival; PRC: Polycomb repressive complex 2; P53: Tumor protein P53; RFS: Relapse-free survival; SUZ12: Suppressor of zeste 12 homolog; TLC: Total leucocytic count

\section{Acknowledgements}

Part of this work was published as a poster presentation and in the abstract book in Abstracts from the 2019 Lymphoma and Myeloma Congress October 23-26, 2019, New York, NY, November 2019

\section{Authors' contributions}

All authors contributed equally. MS put the aim of the research and the methodology. $\mathrm{HZ}$ was the clinical oncologist, who was concerned by the treatment and clinical follow-up. NB and NS had edited and revised the manuscript. FA is the corresponding author who collected the data, performed the PCR experiments, and performed the statistical analysis. All authors have read and approved the final manuscript.

\section{Funding}

The study was funded by Cairo University (as post-graduate research).

\section{Availability of data and materials}

All data will be available upon request after acceptance. Informed consent was obtained from cases and controls.

\section{Declarations}

\section{Ethics approval and consent to participate}

The study was approved by both clinical pathology and clinical oncology departments as well as post-graduate committee as part of the MD thesis fulfillment; the reference number is $1-351015$. Written informed consent was obtained from all subjects included in the study.

\section{Consent for publication}

No identifiable data were used in the study. However, written informed consent for participation was obtained from all participants.

\section{Competing interests}

The authors declare that they have no competing interests.

\section{Author details}

${ }^{1}$ Clinical and Chemical Pathology Department, Kasr Al-Ainy School of Medicine, Cairo University, Kasr Al-Ainy St., 11562 Giza, Egypt. ${ }^{2}$ Clinical Oncology Department, Kasr Al-Ainy School of Medicine, Cairo University, Kasr Al-Ainy St., 11562 Giza, Egypt.

Received: 23 February 2021 Accepted: 27 May 2021

Published online: 25 June 2021

\section{References}

1. Zhang X, Meyerson M (2020) Illuminating the noncoding genome in cancer. Nature Cancer 1(9):864-872. https://doi.org/10.1038/s43018-020-00114-3

2. Diamantopoulos MA, Tsiakanikas P, Scorilas A (2018) Non-coding RNAs: the riddle of the transcriptome and their perspectives in cancer. Ann Transl Med 6(12):241. https://doi.org/10.21037/atm.2018.06.10

3. Grixti JM, Ayers D (2020) Long noncoding RNAs and their link to cancer. Non-Coding RNA Res 5(2):77-82. https://doi.org/10.1016/j.ncrna.2020.04.003

4. Jin K-T, Lu Z-B, LV J-Q, Zhang J-G (2020) The role of long non-coding RNAs in mediating chemoresistance by modulating autophagy in cancer. RNA Biol 17(12):1727-1740. https://doi.org/10.1080/15476286.2020.1737787

5. Yuan C, Ning Y, Pan Y (2020) Emerging roles of HOTAIR in human cancer. J Cell Biochem 121(5-6):3235-3247. https://doi.org/10.1002/jcb.29591
6. Toy HI, Okmen D, Kontou PI, Georgakilas AG, Pavlopoulou A (2019) HOTAIR as a prognostic predictor for diverse human cancers: a meta- and bioinformatics analysis. Cancers 11(6):778. https://doi.org/10.3390/cancers11 060778

7. Kim JO, Jun HH, Kim EJ, Lee JY, Park HS, Ryu CS, Kim S, Oh D, Kim JW, Kim NK (2020) Genetic variants of HOTAIR associated with colorectal cancer susceptibility and mortality. Front Oncol 10:72. https://doi.org/10.3389/ fonc.2020.00072

8. Li C, Cui J, Zou L, Zhu L, Wei W (2020) Bioinformatics analysis of the expression of $\mathrm{HOXC13}$ and its role in the prognosis of breast cancer. Oncol Lett 19(1):899-907. https://doi.org/10.3892/ol.2019.11140

9. Liu Y, Chen X, Chen X, Liu J, Gu H, Fan R, Ge H (2020) Long non-coding RNA HOTAIR knockdown enhances radiosensitivity through regulating microRNA-93/ATG12 axis in colorectal cancer. Cell Death Dis 11(3):175. https://doi.org/10.1038/s41419-020-2268-8

10. Kiyoi H, Kawashima N, Ishikawa Y (2020) FLT3 mutations in acute myeloid leukemia: therapeutic paradigm beyond inhibitor development. Cancer Sci $111(2): 312-322$. https://doi.org/10.1111/cas.14274

11. Bazarbachi A, Bug G, Baron F, Brissot E, Ciceri F, Dalle IA, Döhner H, Esteve J, Floisand Y, Giebel S, Gilleece M, Gorin NC, Jabbour E, Aljurf M, Kantarjian H, Kharfan-Dabaja M, Labopin M, Lanza F, Malard F, Peric Z, Prebet T, Ravandi F, Ruggeri A, Sanz J, Schmid C, Shouval R, Spyridonidis A, Versluis J, Vey N, Savani BN, Nagler A, Mohty M (2020) Clinical practice recommendation on hematopoietic stem cell transplantation for acute myeloid leukemia patients with FLT3-internal tandem duplication: a position statement from the Acute Leukemia Working Party of the European Society for Blood and Marrow Transplantation. Haematologica 105(6):1507-1516. https://doi.org/1 0.3324/haematol.2019.243410

12. Bacher U, Porret N, Joncourt R, Sanz J, Aliu N, Wiedemann G, Jeker B, Banz Y, Pabst T (2018) Pitfalls in the molecular follow up of NPM1 mutant acute myeloid leukemia. Haematologica 103(10):e486-e488. https://doi.org/1 0.3324/haematol.2018.192104

13. Mitrea DM, Kriwacki RW (2018) On the relationship status for Arf and NPM1 - it's complicated. FEBS J 285(5):828-831. https://doi.org/10.1111/febs.14407

14. Kunchala P, Kuravi S, Jensen R, McGuirk J, Balusu R (2018) When the good go bad: mutant NPM1 in acute myeloid leukemia. Blood Rev 32(3):167-183. https://doi.org/10.1016/j.blre.2017.11.001

15. Papaioannou D, Petri A, Dovey OM, Terreri S, Wang E, Collins FA, Woodward LA, Walker AE, Nicolet D, Pepe F, Kumchala P, Bill M, Walker CJ, Karunasiri M, Mrózek K, Gardner ML, Camilotto V, Zitzer N, Cooper UL, Cai X, Rong-Mullins X, Kohlschmidt J, Archer KJ, Freitas MA, Zheng Y, Lee RJ, Aifantis I, Vassiliou G, Singh G, Kauppinen S, Bloomfield CD, Dorrance AM, Garzon R (2019) The long non-coding RNA HOXB-AS3 regulates ribosomal RNA transcription in NPM1-mutated acute myeloid leukemia. Nat Commun 10(1):5351. https:// doi.org/10.1038/s41467-019-13259-2

16. Huet S, Jallades L, Charlot C, Chabane K, Nicolini FE, Michallet et al (2013) New quantitative method to identify NPM1 mutations in acute myeloid leukaemia. Leukemia Res Treat:1-5. https://doi.org/10.1155/2013/756703

17. Tan AYC, Westerman DA, Carney DA, Seymour JF, Juneja S, Dobrovic A (2008) Detection of NPM1 exon 12 mutations and FLT3 - internal tandem duplications by high resolution melting analysis in normal karyotype acute myeloid leukemia. J Hematol Oncol 1:10. https://doi.org/10.1186/17568722-1-10

18. Wu S, Zheng C, Chen S, Cai X, Shi Y, Lin B, Chen Y (2015) Overexpression of long non-coding RNA HOTAIR predicts a poor prognosis in patients with acute myeloid leukemia. Oncol Lett 10(4):2410-2414. https://doi.org/10.3 892/ol.2015.3552

19. Rao X, Huang X, Zhou Z, Lin X (2013) An improvement of the $2^{\wedge}$ (-delta delta CT) method for quantitative real-time polymerase chain reaction data analysis. Biostat Bioinform Biomath 3(3):71-85 https:/pubmed.ncbi.nlm.nih.gov/25558171

20. Gutschner T, Richtig G, Haemmerle M, Pichler M (2018) From biomarkers to therapeutic targets-the promises and perils of long non-coding RNAs in cancer. Cancer Metastasis Rev 37(1):83-105. https://doi.org/10.1007/s10555017-9718-5

21. Dhall A, Zee BM, Yan F, Blanco MA (2019) Intersection of epigenetic and metabolic regulation of histone modifications in acute myeloid leukemia. Front Oncol 9:432 https://www.frontiersin.org/article/10.3389/fonc.2019. 00432,9

22. Li J, Ahn JH, Wang GG (2019) Understanding histone H3 lysine 36 methylation and its deregulation in disease. Cell Mol Life Sci 76(15):28992916. https://doi.org/10.1007/s00018-019-03144-y 
23. Martin CJ, Moorehead RA (2020) Polycomb repressor complex 2 function in breast cancer (review). Int J Oncol 57(5):1085-1094. https://doi.org/10.3892/ ijo.2020.5122

24. Papaioannou D, Nicolet D, Volinia S, Mrózek K, Yan P. Bundschuh, R, et al., (2017). Prognostic and biologic significance of long non-coding RNA profiling in younger adults with cytogenetically normal acute myeloid leukemia. Haematologica, 102(8), 1391-1400 doi: https://doi.org/10.3324/ha ematol.2017.166215

25. Tang Q, Hann SS (2018) HOTAIR: an oncogenic long non-coding RNA in human cancer. Cell Physiol Biochem 47(3):893-913. https://doi.org/10.1159/ 000490131

26. Box J, Paquet N, Adams M, Boucher D, Bolderson E, O'Byrne K et al (2016) Nucleophosmin: from structure and function to disease development. BMC Mol Biol 17(1):19. https://doi.org/10.1186/s12867-016-0073-9

27. Gaballa S, Saliba R, Oran B, Brammer JE, Chen J, Rondon G, Alousi AM, Kebriaei P, Marin D, Popat UR, Andersson BS, Shpall EJ, Jabbour E, Daver N, Andreeff M, Ravandi F, Cortes J, Patel K, Champlin RE, Ciurea SO (2017) Relapse risk and survival in patients with FLT3 mutated acute myeloid leukemia undergoing stem cell transplantation. Am J Hematol. 92(4):331337. https://doi.org/10.1002/ajh.24632

28. Wang S-L, Huang Y, Su R, Yu Y-Y (2019) Silencing long non-coding RNA HOTAIR exerts anti-oncogenic effect on human acute myeloid leukemia via demethylation of HOXA5 by inhibiting Dnmt3b. Cancer Cell Int 19(1):114. https://doi.org/10.1186/s12935-019-0808-z

29. Vu TT, Stölzel F, Wang KW, Röllig C, Tursky ML, Molloy TJ, Ma DD (2020) miR-10a as a therapeutic target and predictive biomarker for MDM2 inhibition in acute myeloid leukemia. Leukemia. https://doi.org/10.1038/s413 75-020-01095-Z

30. Zhai N, Xia Y, Yin R, Liu J, Gao F (2016) A negative regulation loop of long noncoding RNA HOTAIR and p53 in non-small-cell lung cancer. Onco Targets Ther. 9:5713-5720. https://doi.org/10.2147/OTT.S110219

31. Botti G, Scognamiglio G, Aquino G, Liguori G, Cantile M (2019) LncRNA HOTAIR in tumor microenvironment: what role? Int J Mol Sci 20(9). https:// doi.org/10.3390/ijms20092279

32. Stojanovski BM, Hunter GA, Na I, Uversky VN, Jiang RHY, Ferreira GC (2019) 5-Aminolevulinate synthase catalysis: the catcher in heme biosynthesis. Mol Genet Metab 128(3):178-189. https://doi.org/10.1016/j.ymgme.2019.06.003

33. Zhang Y-Y, Huang S-H, Zhou H-R, Chen C, Tian L-H, Shen J-Z (2016) Role of HOTAIR in the diagnosis and prognosis of acute leukemia. Oncol Rep 36(6): 3113-3122. https://doi.org/10.3892/or.2016.5147

34. Göllner S, Oellerich T, Agrawal-Singh S, Schenk T, Klein H, Rohde C et al (2017) Loss of the histone methyltransferase EZH2 induces resistance to multiple drugs in acute myeloid leukemia. Nat Med 23(1):69-78. https://doi. org/10.1038/nm.4247

\section{Publisher's Note}

Springer Nature remains neutral with regard to jurisdictional claims in published maps and institutional affiliations.

\section{Submit your manuscript to a SpringerOpen ${ }^{\circ}$ journal and benefit from:}

- Convenient online submission

- Rigorous peer review

- Open access: articles freely available online

- High visibility within the field

- Retaining the copyright to your article

Submit your next manuscript at $\boldsymbol{\nabla}$ springeropen.com 